\title{
An economic analysis on internet regulation in China and proposals to policy and law makers
}

\author{
Zhixiong Liao \\ Faculty of Law, \\ University of Waikato, \\ Private Bag 3105, \\ Hamilton 3240, New Zealand \\ Email: zliao@waikato.ac.nz
}

\begin{abstract}
China has enacted and enforced 70-more internet-regulation related pieces of laws and regulations, and the so-called 'real name registration' scheme is to be implemented by the end of June 2014. To date, China has established comprehensive legal framework and sophisticated multi-level law enforcement mechanism to regulate the contents on internet. This paper undertakes an economic analysis of the internet contents regulation in China, aiming to find out a possible answer to the question of whether the current regulation regime in China on internet contents is cost-effective, feasible and maintainable and hence justifiable and desirable, taking into account the short-term and long-term welfare of the community. Based on the analysis, this paper makes submissions to policy and law makers accordingly.
\end{abstract}

Keywords: economic analysis; internet regulation; policy; law; China.

Reference to this paper should be made as follows: Liao, Z. (2016) 'An economic analysis on internet regulation in China and proposals to policy and law makers', Int. J. Technology Policy and Law, Vol. 2, Nos. 2/3/4, pp.242-256.

Biographical notes: Zhixiong Liao has practised law in China, both in public sectors and in private law firms, since 1996, specialised in commercial law, overseas investment and tax law, with some Hong Kong listed companies, Fortune-500 subsidiaries and local tax departments as his clients. He was admitted as a Barrister and Solicitor of New Zealand High Court and practised commercial/property law in Auckland law firms before joining the Faculty of Law. He is also a member of the New Zealand Society of Translators and Interpreters, specialised in legal translation. His main research interests are contract/commercial law and business regulation.

\section{Introduction}

China has enacted and enforced 70-more internet-regulation related pieces of laws and regulations (Liao, 2015), and the so-called 'real name registration' scheme is to be implemented by the end of June 2014 (State Council Office, 2014). To date, China has established comprehensive legal framework and sophisticated multi-level law enforcement mechanism to regulate the contents on internet. A number of levels/measures of law enforcement are employed by the Chinese Government to regulate 
the internet in China, namely, content restrictions; licensing requirements; liability imposed on ISPs and ICPs; registration requirements of IP address, user ID and account; self-regulation coupled with online surveillance, liabilities imposed on internet users; technical measures and human censorship. Presumably, policy makers, lawmakers, and netizens, whether within China or not, are interested in knowing whether such this legal framework and law enforcement mechanism are cost-effective, and whether the current internet content regulation regime in China as a whole is maintainable and justifiable from an 'economic' point of view, and whether the on-coming 'real name registration' scheme will substantially change the answers to those questions. This paper attempts to do an economic analysis on China's current internet content regulation regime and based on the findings makes submissions to policy and law makers accordingly.

Although an 'economic' analysis, it is unlikely to be a quantitative research in a strict sense. Rather, this paper adopts a substantially qualitative approach by observation and comparison of the 'effects' and 'costs' of the current internet content regulation regime in China. By the term 'effect', this paper refers to the 'positive' effects brought by the internet regulation, mainly the desired effects from the regulators' standpoint, and the benefits brought to the society. ${ }^{1}$ The term 'cost' covers both the direct costs and indirect costs. Direct costs represent the costs incurred for the purpose of, and in the course of, the establishment and implementation of the internet regulation. Indirect costs represent the costs that are resulted from the internet regulation in China, i.e., the 'negative effects' resulted from the regulation (Liao, 2004). In some circumstances, 'effect' and 'cost' could be interchangeable, for example, some effects desired by regulator (the Chinese policy and law maker) could be a cost to netizens and the international community. These are the starting points of this analysis.

\section{Internet architecture and its implications for internet content regulation}

Any governmental regulation of an industry has its effects and costs and the internet content regulation in China is of no exception. However, because of the uniqueness of the internet architecture and the sophisticated nature of the internet regulation in China, in evaluating the effects and costs of China's current internet content regulation regime, two factors must be taken into account. One is China's basic attitudes towards the internet and the goals of its internet regulation. The other is the internet architecture and its implications for the regulation of internet content.

One might argue that there is no real difference between the regulations of the contents on the internet and the contents communicated through other forms of media, because the focus of the regulation is the content being communicated rather than the means of communication. It is true that the internet is one of many ways to communicate and disseminate information. If the only role of the internet were to substitute for other communication media, the problems for the content regulation would have no real difference between the internet and other forms of media. However, the infrastructure or architecture of the internet is so unique or so different from other forms of media that the internet does pose different problems to the internet content regulators (Solum, 2009).

There are some ideas/theories proposed in relation to the internet architecture (or the distinctive character of the internet) and its implications for internet regulation, for 
example, the code thesis, the end-to-end principle and the layers principle. These theories/ideas provide frameworks for analysing internet regulation.

The code thesis claims that the nature of the internet or cyberspace is determined by the code - the software and hardware that implements the internet; therefore, the code is the primary regulator in cyberspace (Lessig, 1999; Solum and Chung, 2004). Internet cannot be regulated by national governments because the internet is a global network of networks, and activity on the internet can originate in any physical location in the world (Hughes, 2003).

The end-to-end principle argues that the primary characteristic of the internet architecture that enables innovation is the end-to-end principle, i.e., to keep intelligence in a network at the ends or in the applications, leaving the network itself relatively simple (Id). This principle calls for a 'stupid network' and 'smart applications' (Solum and Chung, 2004). The network simply forwards or routes the data packets and does not discriminate traffic generated by different applications (id).

Solum and Chung (2004) proposed the 'layers principle' based on the layers analysis of the internet. Layers analysis is based on the notion that the internet has been engineered through the use of layers and respecting the integrity of the layers is a 'fundamental principle' of internet design (Id, p.820). The six layers that constitute the internet are (Id):

- the content layer - the symbols and images that are communicated

- the application layer - the programs that use the internet, e.g., the web

- the transport layer - TCP, which breaks the data into packets

- the internet protocol (IP) layer - handles the flow of data over the network

- the link layer - the interface between users' computers and the physical layer

- the physical layer - the copper wire, optical cable, wireless devices, routers, etc.

Layers analysis explains the process of the communication via the internet (Id, pp.816-817):

\begin{abstract}
"The layers are organized in a vertical hierarchy. When information is communicated via the internet, the information flows down from the content layer (the "highest" layer) through the application, transport, IP, and link layers to the physical layer (the "lowest" level); across the physical layer in packets; and then flows back up through the same layers in reverse order. Communication on the internet requires that content be digitalized by an application, and that the digital information be broken into packets by the transport layer and addressed by the internet protocol layer so that it can be passed on by the link layer to the physical layer. Having reached the bottom layer, information then moves horizontally. The physical layer transmits the individual data packets by copper, fiber and/or radio by various waypoints to an endpoint or destination on the network. Once at its destination, the information then ascends vertically through the layers to be interpreted by an application as content."
\end{abstract}

Based on the layers analysis, the 'layers principle' argues that layers are the key and central characteristic of the internet architecture and the legal regulation of the internet should be governed by the layers principle: the law should respect the integrity of layered Intent architecture (Id, pp.815 and 835). The layers principle has two corollaries. The first 
is the principle of layer separation: internet regulation should not violate or compromise the separation between layers designed into the basic architecture of the internet. The second is the principle of minimising layer crossing: minimising the distance between the layer at which the law aims to produce an effect and the layer that is directly affected by legal regulation. The layer principle has obvious implications for the evaluation of internet regulations. The best regulations attack a problem at a given layer with a regulation at that layer; whereas the worst regulations attack a problem at the content layer by imposing a regulation at the physical layer - or vice versa (Id, pp.817-818).

The unique architecture of the internet suggests that the most fundamental nature of the internet is freedom and any governmental regulation on the internet will be largely futile and vain. If a government does insist on regulating the internet, different methods of regulation could have huge difference regarding the effects and costs resulted.

\section{The effect of the internet content regulation in China}

The evaluation of the effect of a governmental regulation must take into account the policy goals of the regulation. Generally, government regulation applies to an industry where 'market failure' would be resulted from the problems of natural monopoly, imbalance of information/bargaining power or external effects. The main policy goals in this situation are the promotion of effective competition and the protection of consumers' rights (Liao, 2004). This is the sort of regulations for economic reasons, which are more acceptable or to be deemed justifiable. However, a government regulation may also be implemented for political, social, cultural or other reasons (Id). As the huge differences in these areas exist in different countries, such kind of regulations is more likely to be controversial and to be criticised than regulations justified by economic reasons.

China's Government welcomes the internet because of the increased and increasing opportunity for economic development and the potential for China to become a global leader in e-commerce (Gao, 2004). However, the development of the internet in China also poses problems to the government because China wants to maintain the Chinese Communists Party (CCP) leadership and the socialist regime (Merrington, 2008; Cullen and Choy, 2005). Therefore, China's Government has two concurrent goals: to utilise the internet for its economic development on one hand; and to limit the citizen's ability to access (and put online) information that may be detriment to the CCP's regime on the other (Cullen and Choy, 2005; McGeary, 2001).

One may then ask - Has China's internet regulation achieved these goals? Leaving aside the issues concerning the costs and/or negative effects of its internet regulation, it can be said that China's Government has achieved both of these goals to a large extent. First, the rapid development and the prevalence of the internet in China demonstrate that China has been utilising the internet in furtherance of its economic growth. Although restrictions have been cited as a major obstacle to the development of the internet in China (McGeary, 2001), as a matter of fact, the internet in China is developing very fast and more and more Chinese citizens are using the internet for a wide range of purposes. By the end of 2013, China leads the world with internet users of 618 million and internet is widely used in business, research and citizen's daily life (CNNIC, 2014a).

Secondly, it is an undeniable fact that most Chinese citizens are precluded from accessing prohibited information via the internet, and that few prohibited contents are 
produced inside the People's Republic of China (PRC) on the internet. This shows that China's Governmental control over the internet contents in China is basically effective. It is true that the filtering system may not be completely effective for the problem of under-inclusion arises from the layer-violations of the blocking. It is also true that a savvy user can break through the filtering system and access prohibited information by employing technological means (Stieglitz, 2007). These factors show that the internet regulation in China has not been successful in completely restricting undesirable conducts and contents from the government's stand points ((McGeary, 2001). However, this does not significantly negate the real impact of the regulation on the populace. Most Chinese citizens do comply with the regulation and do not try to access or publish online the prohibited information. The compliance of Yahoo and Google with Chinese regulation in previous years shows that China is successfully restricting access to the internet through a combination of technology, law, and citizen education (Zittrain and Edelman, 2003). Judged from the Chinese Government's point of view and leaving aside the negative effects, the internet regulation in China is largely effective. It has been commented that China's internet regulation is "the most sophisticated and effective" [Bambauer, (2006), p.56].

It is hard to estimate precisely what the benefits are brought to the society by the internet regulation in China. The Chinese Government may argue that the internet regulation help to maintain the social stability which benefits Chinese citizens and enterprises, and that the control of online pornography and online gambling helps to protect the internet users who are vulnerable to such kinds of social ills.

In relation to the effects of a specific law enforcement mechanism of the internet regulation in China, it seems that different mechanisms produce different effects. For instance, the licensing and registration requirements seem to be very effective to control the internet service providers (ISPs), internet content providers (ICPs) and to force the internet users to self-regulate their online behaviours. The technical measures (such as the filtering at the gateways), however, do not satisfactorily stop the targeted internet users from accessing prohibited contents. On one hand, average internet users in China may not even care about whether a Falun Gong or pro-Tibet website is accessible to them or not so the blocking is meaningless or unnecessary for them; on the other hand, an internet user who wants to access those contents can easily break through the blocking by using proxy servers or other technical tools, which effectively defeats the regulator's objective of putting up the blockades. The different effects produced by different mechanisms may be clearly explained by the application of the layers analysis proposed by Solum and Chung (2004). By imposing the liability upon delinquent internet users, users refrain from accessing and/or producing the prohibited contents, this is a mechanism that the layer at which the law aims to produce an effect and the layer that is directly affected by legal regulation are at the same layer (content layer), which follows the first corollary of the layers principle. Whereas in the circumstances where technologies blocking the IP address, domain name system (DNS), and uniform resource locator (URL) are used, the directly affected layer is not the targeted layer - the content layer itself, the effect of the regulation will be compromised to some extent depending on the 'distance' between the layer at which the law aims to produce an effect and the layer that is directly affected by the technical measures. Human censorship and internet users self-monitoring are the law enforcement mechanisms that interfere the least with the key characteristic of the internet architecture - the layers architecture as proposed by Solum and Chung (2004). In this 
sense, they are the most effective and accurate ways of implementing the censorship laws and regulations.

\section{Costs of the internet content regulation in China}

\subsection{Direct costs}

The direct costs incurred for the purpose of, and in the course of, the internet regulation in China include the resources put in by the Chinese Government, the ISPs and ICPs, and other internet-related business operators.

In order to achieve its goals of internet regulation, the Chinese Government has invested a large amount of resources into the regulation. These include the cost of law-making for the purpose of the internet regulation and the cost of law enforcement in the course of the internet regulation. China has established a comprehensive legal system and multi-level enforcement mechanisms for internet regulation (Liao, 2015). The comprehensive legislation for internet regulation consists of more than 70 pieces of statutes and regulations concerning the internet regulation (Liao, 2015). It is conceivable that the cost of the establishing of the legal framework and the cost of the making of each law/regulation are tremendous, which at least include the costs of law-making plan, collection of relevant information, drafting of the law/regulation, public submission and hearing (some), revision of the draft and passing of the law/regulation.

The direct costs incurred in the course of implementation of the internet regulation in China are even much more significant than the costs incurred at the law-making stage. ${ }^{2}$ First, the publication and dissemination of the law/regulation incur expenditure. A law must be known to the employees of the law enforcement agencies and the internet users and relevant ISPs and ICPs in order to be effective in the real world. In order for the employees of the internet regulation agencies and/or the ICPs and ISPs to be familiar with the up-to-date government regulations, ongoing training will be invariably required. Secondly, the government must establish regulatory agencies and hire government employees in order to effective the regulation system, which generates tremendous administrative costs. For example, internet surveillance divisions in charge of the internet content surveillance were set up under the Ministry of Public Security and local public security authorities, which employ a cyber-police squads specifically dealing with 'internet crimes'. Cherry (2005) estimates that the Chinese Government employs an internet police force with between 30,000 and 50,000 members. As the regulations impose the licensing requirements on ISPs, ICPs and internet Café operators, there must be other well-trained government officials to handle the assessment of the applications and to make decisions. The surveillance of the online contents and the registration of basic information (e.g., ID, IP addresses, locations of businesses and servers) of internet users and internet business operators also require human resources. Thirdly, the hardware and software used for the internet content filtering are expensive and must be replaced or updated from time to time. It is reported that the Golden Shield Project has cost RMB3.712 billion until 2010 (Legal Daily, 2010). Recently, a local police office in Wenzhou City applied for RMB149,000 Yuan for purchasing of Trojan virus for the interference with mobile network use (Chen, 2015). Fourthly, the ISPs, ICPs and internet café operators must put in a considerable amount of resources (investment in equipment, software and human resources, etc.) to comply with the internet regulation requirements 
including to discover, filter, stop transmission and report to regulatory bodies the 'sensitive information'. The annual assessments and renewal of internet license process costs both the government agencies and the internet-related businesses.

It should also be noted that all of the direct costs stated above are social costs rather than individual costs. Social cost is the net loss of social wealth whereas individual cost is cost to some members of the society but benefit to the others and hence is simply a redistribution of the social wealth (Liao, 2004).

\subsection{Indirect costs}

The indirect costs are the negative effects resulted from the internet regulation in China. These costs include the cost of the Chinese internet users' rights and the loss of efficiency of the internet.

The restriction of Chinese netizens' rights is obvious. If there were no such a regulation, Chinese citizens would have the right to access any information widely available on the internet; they would also have more freedom of speech online. For fear of being punished by the government or for the technical filtering system installed, they refrain from doing or are not able (not as easily as it should have been) to do what they should have been entitled to do (Liao, 2015).

The other indirect cost is the loss of efficiency of the internet resulted from the regulation. Not only the internet users within China, but also those in the rest of the world have to bear the loss. This is a reasonable and logical inference from the impact of the governmental regulation on the architecture of the internet.

Applying the layers principle on the internet architecture, we can see the internet regulation in China results in the loss of efficiency of the internet in many aspects. First, it is more difficult for the internet users in China to assess the information they need, including not only the prohibited contents, but also other information. This is because the cross-layered regulation impact substantial innocent uses for the so-called 'over-breadth' [Solum and Chung, (2004), p.819] problem. For example, the author, with a group of Waikato Law students, while staying in China in December 2014, experienced tremendous difficulties in using the University of Waikato's Google-based email and other online systems, which resulted in normal academic and business activities extremely tiresome. In addition, the filtering system decreases the speed of data transmission in and out the PRC because routers are not designed to block IP addresses or websites (McGeary, 2001) and the information has to pass through the limited number of gateways. For these reasons, internet users in China suffer loss of efficiency resulted from the filtering system.

Secondly, the centralised topology of the internet infrastructure in China is inconsistent with one of the basic ideas of the architecture of the internet - the packet switched network. Information (e.g., a PDF document, or an application) is broken into a large amounts of packets (each of the size of $200 \mathrm{kB}$ ) and packets are transmitted through routers in a hop-by-hop way (Solum and Chung, 2004). As the internet in China form a part of the whole internet, even if the destination of the delivery of information (e.g., a PDF document) is not within China, some of the packets may still pass through the internet in China. However, given that the centralised topology of the internet infrastructure in China keeps the network in China connected to only a limited number of gateways and filtering systems are installed at the gateways, it becomes harder and slower for any packets to pass through the internet network in China than otherwise. 
Worse still, because of the filtering system, users outside China cannot use millions of routers used inside China (Id). Packets may also be dropped outside the gateways even though the destination of the packet is outside China (Id).

Thirdly, the filtering system installed in China undermines the transparency of the whole internet. The internet simply transmits the capsulated packets without discrimination based on what the contents are. Transparency or non-discrimination of the internet enables anyone to transmit information including application software on the internet without bureaucracy. For this reason, the internet creates an environment conducive to innovation at a very low cost. Layer-violating regulations inherently undermine the transparency of the internet, and as a result, it increases the cost of innovation (Id).

\section{Implications of the 'real name registration' on the cost-effectiveness}

By the so-called 'real name registration' regime, Chinese Government imposes on internet-related business operators the obligation to request and register evidence of the 'true identity' of internet users in China. ${ }^{3}$ The implementation of this regime will make Chinese Government's internet content regulation more effective from its own point of view. First, 'real name registration' will render the investigation of violators of internet related laws and regulations easier and hence lower the cost incurred in investigation and prosecution. Secondly, the 'real name registration' will frighten Chinese netizens and deter them from breach of the laws and regulations on internet contents. Lower cost for investigation and prosecution generally means law breakers are more likely to be actually punished. Thirdly, as the Chinese Government argues, the 'real name registration' of internet users will result in a more effective of protection of personal information and privacy of citizens (Cui et al., 2012).

On the other hand, however, the law/regulation making and enforcement of the 'real name regulation' regime have some direct costs. In order to provide a high level legal authority of the regime, China's legislature, the National People's Congress Standing Committee (NPC Standing Committee, 2012) passed a statute titled 'Decisions on strengthening the protection of network information'. There should have been general costs incurred in the making of this statute. In addition, the Ministry of Industry and Information, National Office of internet Information and Ministry of Public Security are required to make detailed regulations and implement the 'real name registration' (State Council Office, 2013), which inevitably result in costs in the making and enforcement of the regulations. ISPs, ICPs and internet users in China will also have to bear direct costs - compliance costs.

The 'real name registration' is a 'one stone, two birds' scheme (Liao, 2015). It could also be argued that while the 'real name registration' may reduce the overall direct cost of the enforcement of the laws and regulations on internet contents in China and may bring some 'positive effects' in protection of privacy and personal information, the tightening up of the control of the internet content may also result in considerable indirect cost - the net loss of netizens' benefit in two aspects, namely, Chinese netizens' freedom of expression is further restricted, and the global community is less likely to share information and thoughts from China. The Chinese Government may also suffer indirect 
cost by losing support from netizens especially the well-educated middle class in China and losing reputation for tightening up censorship on the internet.

It is submitted, therefore, that the oncoming 'real name registration' will not substantially change the overall cost-effectiveness of China's regulation of internet contents.

\section{Suggestions and proposal to policy and law makers}

\subsection{Suggestions to western policy makers}

\subsubsection{Understand the political, social and legal environment in China}

Internet regulation in China is not an independent phenomenon. Rather, it is a part of the whole governmental control system. In order to have a better understanding of the internet regulation in China and to make 'proper' policies addressing the concerns arising from China's internet content regulation, the Western policy makers (especially those of the USA) should first understand the unique political, social and legal environments in China.

Law is largely based on and closely connected with politics and this is even more so in China. Different governments may have different opinions as to what kinds of information are illegal and thus should be prohibited from being published or disseminated on the internet or through other types of media. For example, as China regards Falun Gong as an illegal organisation threatening the social stability of China, any information promoting Falun Gong is deemed illegal and is prohibited. However, from a Westerner's perspectives, Falun Gong may simply be seen as a religious group and China's prohibition of it amounts to a violation of human rights (freedom of expression and freedom of religion). A brief study of China's history may help to understand the position of the Chinese Government. In China's long history, religious groups were not uncommonly used as disguises by political organisations aiming to overturn the incumbent government. ${ }^{4}$ It is inappropriate for the US Government to provide funds to break through the Chinese Government control over the internet contents promoting Falun Gong [Pan, (2006), p.Al 1]. What if China's Government also provides funds and technologies to some Islamic extremist groups to break through the FBI's surveillance over 'terrorism promotions'? Can the Chinese Government argue that the FBI is limiting the human right of freedom of expression/religion?

\subsubsection{Know more about internet users in China}

The Western policy makers should also know more about the internet users in China. What are the main purposes of their internet uses? What are the effects of the Chinese culture and economic development on the internet users? What are the Chinese citizens' understanding of state sovereignty, state unity and territory integrity, Tibet independence movement, China's territory claim over Taiwan and their views on Falun Gong? Who are affected by the content regulation and to what extent?

It is suggested that Chinese internet users do not rely on their highly-censored internet for information or business communication, but instead, primarily for entertainment and discussion; and that they do not care too much about the content regulation of the internet in China (Thompson, 2006).). This is not, however, the whole picture. In fact, there are a 
variety of purposes underlying the internet uses in China. However, few of the internet users are actually affected by the content regulation to a substantial extent. In China, if you are conducting an academic research, you can obtain the information needed online and can easily access the US Parliament Library. If you are doing business in China, you can access information about almost any stock markets in the World and any other business information you need. You can also have a live video conference with your overseas business partner by using MSN, Skype, e-mail, and other instant messaging software. If you surf the internet for entertainment, you can download music and movies as many as you like. And most surprisingly, you can also easily access many pornographic materials online without the need of employing any sophisticated computer techniques. There has been no real punishment for visiting porn websites in China although pornographic contents are said to be prohibited by law (Liao, 2015). Most Chinese citizens do not care much about the censorship because they can do almost all what they want on the internet (Thompson, 2006).

In addition, in light of Chinese culture and history, most Chinese people do not really care about politics and few of them have sympathy for Falun Gong and its practitioners. However, most Chinese people, even those opposing the socialist regime, take for granted that Tibet and Taiwan are inalienable parts of China. It seems that only a very small fraction of the internet users in China are substantially affected by the content regulation, leaving aside the negative effect that the filtering system may lower the efficiency of their assess to the desired information, as discussed above.

On the other hand, with the economic development in China, there are more and more "white-collar urban professionals in the major Chinese cities" (Thompson, 2006). They do care about political issues and their rights and freedoms. This emerging middle class has started to exert their influence over the shaping of the internet regulation policies in China. For example, in May 2009, the MIIT informed PC manufacturers that all computers sold in China after the stipulated deadline would have to be pre-installed with Chinese web-filtering software known as 'Green Dam' (VOA, 2009a). A Beijing artist proposed a 24-hour internet boycott "to let people know what our attitude is towards this kind of censorship" (VOA, 2009b). Eventually the Chinese Government indefinitely 'delayed' the plan in face of the widespread pressure and criticism of the software from the public and industrial groups (Id). Up to date, five years after, that plan has not yet been actually implemented. Furthermore, the rapid development of mobile network in China is turning more and more Chinese citizens into netizens which substantially expand internet users (and as stakeholders) beyond 'middle class'. By the end of June 2014, there have been 527 million mobile phone internet users in China (CNNIC, 2014b). Although Facebook, YouTube, Twitter cannot be used in China without using effective proxies, their 'equivalents' such as Renren, Youku, Weibo and WeChat provides Chinese netizens with means to share information quickly. Many overseas Chinese also use WeChat who shares via 'groups' or 'moment' all kinds of information with their family members, friends and previous classmates and colleagues, which turns more and more Chinese now care more about their rights and freedom. Knowing more about the outside world, internet users are now braver to resist against government abuse of power.

\subsubsection{Be patient and keep mild but constant efforts}

In the USA, a bill titled 'Global Online Freedom Act' was introduced to the House of Representatives in 2006, and was reintroduced and referred to the House Energy 
and Commerce Committee in May 2009 and December 2011 for consideration (Govertract.us, 2011). The purpose of the bill was "to prevent United States businesses from cooperating with repressive governments in transforming the internet into a tool of censorship and surveillance, to fulfil the responsibility of the US Government to promote freedom of expression on the internet, to restore public confidence in the integrity of US businesses, and for other purposes" (Id). If the bill is passed, many US IT companies operating in internet-related business in China will be punished for their compliances with the Chinese laws and regulations on internet regulation, or they have to leave the Chinese market in order to avoid legal sanctions by the US regulators. It is suggested that this bill is seeking to attack the free speech problem in the American way - directly and with a 'big bang', and not the Chinese way (Smith, 2008). The direct outcome of the enactment will be to force the US IT companies to exit the Chinese market rather than to exert any meaningful pressure on China to change its policy on regulating the internet contents. It is a mistaken belief that China will change its internet regulation policy for fear of losing the US companies' investments and technologies (Id, p.526). The Chinese internet market has the capability to exist without US technologies (Id, p.528). The direct and 'big bang' American way will result in that the US IT companies being forced to leave China and losing the opportunity to contribute to expand the freedom of expression in China (Id). The fact that Baidu has took over Google's position in China is a good illustration. Chinese people feel more comfortable to accept a mild and gradual change than the US law-makers would otherwise indulge themselves in thinking. Therefore, the Western policy/law makers must be patient and maintain a positive attitude towards internet liberalisation in China if they really care about facilitating Chinese citizen's freedom of expression online.

\subsection{Proposals for Chinese policy/law makers}

In an era of 'globalisation', China should be a responsible and reliable member of the 'global village' and should contribute to promote the collective welfare of the international community. In relation to its content regulation on the internet, China should observe its international obligations and respect the internet architecture.

\subsubsection{Observe China's international obligations}

China is a signatory of the International Covenant on Civil and Political Rights (United Nations, 2015), article 19(2) of which provides that everyone shall have the right to freedom of expression including freedom to seek, receive and impart information and ideas of all kinds, regardless of frontiers, through any media of his choice.

China has the legal obligation to ensure its citizens' freedom of expression, including the right of access information on the internet without interference and regardless of frontiers. It is arguable that some content regulation on the internet by a national government is justifiable, for instance, the restriction of child pornography. However, the regulation should be put in place for bona fide purposes and in good faith. The implementation of the regulation should impair the fundamental human rights as little as reasonably necessary. This requires the Chinese Government to narrow the coverage of its internet content regulation. The least interference policy will also improve the cost-effectiveness of China's internet regulation. 


\subsubsection{Respect the internet architecture}

As discuss above, the layered architecture of the internet requires national governments to respect the layer principle and its two corollaries in internet regulation. The first corollary, the principle of layer separation, directs public internet regulators not to violate or compromise the separation between layers designed into the basic architecture of the internet (Solum and Chung, 2004). The second corollary, the principle of minimising layer crossing, directs internet regulators to minimise the distance between the layer at which the law aims to produce an effect and the layer directly targeted by legal regulation (Id).

As Liao (2015) shows, Chinese Government adopts a number of measures to enforce its law and regulations on internet content control. Different measures have different effects and incur different costs. Chinese Government should choose non-layer-violating regulation measures as far as it can. For example, policing net café users in the business sites and registering their identity, imposing legal liabilities and harsh penalties on delinquent internet users to facilitate their self-regulation, and human censorship are effective (although costing human resources) and non-layer-violating measures to enforce the content control. If cross-layer filtering system is used for certain reasons, the government should select those with least interference with the internet layer architecture. For example, not to block the IP address if blocking the URL of a specific webpage can achieve the regulatory objectives (Solum and Chung, 2004).

\subsection{Proposals for both}

Although there are huge disagreements between the Westerners and the Chinese Government as to what should be restricted on the internet, there are still certain contents that should be controlled on the internet without too many controversies, for instance, child pornography, copyright infringements and materials promoting terrorism. In addition, both the West and the Chinese Government have common interests in maintaining the transparency of the internet. Therefore, both the western and Chinese policy makers should try to achieve mutual understanding and cooperation as a joint effort to regulate online activities effectively in those areas, and to preserve the common wealth of the human beings - the transparent and layer-structured internet.

\section{Conclusions}

China has the most sophisticated internet regulation regime in the world. A variety of laws and regulations were made and a number of levels/measures of law enforcement are employed by the Chinese Government in order to regulate the internet contents in China.

The economic analysis of the internet regulation in China has borrowed economics notions to analyse the effects and costs of the regulation. The aim is to find out whether China has achieved its goals of the internet regulation and whether its internet content regulation is effective and maintainable. It seems that the internet regulation in China has achieved, to a large extent, the Chinese Government's dual goals: to utilise the internet in furtherance of its economic growth and to restrict the political impact of the internet, despite the huge social costs of regulation incurred by the regulation. The layers analysis shows that China's internet content regulation is not completely effective because of the 
layer violations. In particular, the technical blocking measures and the centralised topology of the internet structure in China are contrary to the fundamental characteristic of the internet - the layered architecture. Hence, they are ineffective for both overbreadth and under-inclusion. They have significant negative effects not only on the internet users in China, but also on those in the rest of the world. The analysis also suggests that the different law enforcement measures of the internet regulation in China have different degrees of interference with the basic architecture of the internet and thus have different effects. Measures directly targeting the content layer (e.g., human censorship, internet users' self-censorship) or crossing least layers are more effective and have less negative effects.

Following the economic analysis, it can be said that the internet regulation in China is by and large successful in terms of achieving Chinese Government's policy goals notwithstanding the huge direct costs and significant negative effects. Contrary to some suggestions, taking into account the unique political, legal and social-cultural environment in China, it is submitted that the internet regulation in China is maintainable. This is because the contents regulated are becoming increasingly selective in the regulation practice and most Chinese citizens can use the internet for their professional and personal life and enjoy a level of freedom of expression which would be unimaginable a decade ago. The internet-regulation-related incidents that occurred recently in China do not herald a substantial change of China's overall policy on internet content regulation. Rather, they could be seen as an application of the Chinese Government's flexible and utilitarian approach in respect of the law enforcement of the internet regulation. Proposals are thus made accordingly to the Western and Chinese policy and law makers regarding the internet content regulation in China.

It is very likely that a detailed quantitative research based on empirical data would support the submissions by this paper, but this entails another substantive research project.

\section{References}

Bambauer, D. (2006) 'Cool tools for tyrants: the latest American technology helps the Chinese Government and other repressive regimes clamp down', Legalaffair.org, January-February [online] http://www.legalaffairs.org/issues/January-February2006/feature_bambauer_janfeb06.msp (accessed 28 January 2015).

Chen, X. (2015) 'A branch of Wenzhou Public Security Bureau was alleged of purchasing Trojan virus, police should explain without delay', People.cn, 9 January [online] http://yuqing.people.com.cn/n/2015/0109/c367510-26357890.html (accessed 28 January 2015).

Cherry, S. (2005) 'The net effect, IEEE spectrum online', incommunicado.info, June [online] http://www.incommunicado.info/node/176 (accessed 15 August 2010).

CNNIC (2014a) The 33rd Statistical Report on internet Development in China, China Internet Network Information Center, 5 March [online] http://www.cnnic.net.cn/hlwfzyj/hlwxzbg/hlwtjbg/201403/t20140305_46240.htm (21 March 2014)

CNNIC (2014b) Report on China's Mobile Internet 2013-2014, China Internet Network Information Center, 26 August [online] http://www.cnnic.net.cn/hlwfzyj/hlwxzbg/ydhlwbg/201408/t20140826_47880.htm (accessed 28 January 2015). 
Cui, Q., Chen, F. and Zhou, W. (2012) China is to have New Law Focusing on Protect of Citizen's Electronic Personal Information, Xinhua, 24 December [online] http://www.npc.gov.cn/npc/xinwen/2012-12/25/content_1748314.htm (accessed 28 January 2015).

Cullen, R. and Choy, D.W. (2005) 'China's media: the impact of the internet', Int'l. L. J., Vol. 6, No. 323, pp.323-339, San Diego.

Gao, F. (2004) 'The e-commerce legal environment in china: status quo and issues', Temp. Int'l. \& Comp. L.J., Vol. 18, No. 51, pp.51-76.

Govertrack.us (2011) 'Global Online Freedom Act of 2009', H.R. 2271, 111th Congress, re-introduced as H.R. 3605, 112th on Dec. 8, 2011), Govertrack.us [online] http://www.govtrack.us/congress/bill.xpd?bill=h111-2271 (accessed 27 March 2014).

Hughes, J. (2003) The Internet and the Persistence of Law, 44 B.C. L. Rev. 359, pp.359-396.

Legal Daily (2010) Public Security Technology is a Strong Support of Police Affairs: Visiting Runsen Li, Director of Science and Technology Committee of Ministry of Public Security', Legaldaily.com.cn, 12 January [online] http://www.legaldaily.com.cn/zfb/content/ 2010-01/12/content_2021704.htm?node=20609 (accessed 28 January 2015).

Lessig, L. (1999) Code and Other Laws of Cyberspace, Basic Books, New York.

Liao, Z. (2015) 'Implications of Chinas latest statute on internet and the oncoming real-name registration scheme', International Journal of Technology Policy and Law, Vol. 2, No. 1, pp.55-70.

Liao, Z. (2004) 'A research on the legal system of the regulation of China's market access', in Shi, J. and Deng, F. (Eds.): Economic Law Review, Vol. 4, pp.241-317, China Legal Publishing House, Beijing.

McGeary, A.D. (2001) 'China's great balancing act: maximizing the internet's benefits while limiting its detriments', The International Lawyer, Vol. 35, No. 219, pp.219-230.

Merrington, L. (2008) 'The impact of the internet on the political and media landscape in the People's Republic of China', Melbourne Journal of Politics, Vol. 33, No. 7, pp.7-29.

National People's Congress (NPC) Standing Committee (2012) Decisions on Strengthening the Protection of Network Information, National People's Congress, 28 December [online] http://www.gov.cn/jrzg/2012-12/28/content_2301231.htm (accessed 15 October 2014).

Pan, P.P. (2006) 'Free software takes users around filters', Washington Post, 21 February [online] http://www.washingtonpost.com/wp-dyn/content/article/2006/02/20/AR2006022001305.html (accessed 28 January 72015 ).

Smith, K. (2008) ‘A global first amendment?', J. on Telecomm. \& High Tech. L., Vol. 6, No. 509, pp.509-536.

Solum, L.B. (2009) 'Models of internet governance', in Bygrave, L.A. and Bing, J. (Eds.): Internet Governance, pp 48-91, Oxford Press, New York.

Solum, L.B. and Chung, M. (2004) 'The layers principle: internet architecture and the law', Notre Dame L. Rev., Vol. 79, No. 815, pp.815-948.

State Council Office (2013) Notice on Tasks Assignments regarding the Implementation of State Council's Plan for the Institutional Restructuring of the State Council and Transformation of Functions, State Council Office, 26 March [online] http://www.gov.cn/zwgk/201303/28/content_2364821.htm (accessed 28 January 2015).

Stieglitz, E.J. (2007) 'Anonymity on the Internet: how does it work, who needs it, and what are its policy implications?', Cardozo Arts \& Entertainment L. J., Vol. 24, No. 1395, pp.1395-1417.

Thompson, C. (2006) ‘Google's China problem (and China's Google problem)', New York Times, 23 April [online] http://www.nytimes.com/2006/04/23/magazine/23google.html (accessed 27 March 2014).

United Nations (2015) Treaty Collection, Status as at 11-01-2015, United Nations, 11 January [online] http://treaties.un.org/Pages/ViewDetails.aspx?src=TREATY\&mtdsg_no=IV$4 \&$ chapter $=4 \&$ lang=en\&clang=_en $($ accessed 27 January 2015). 
VOA (2009a) US Protests Chinese Computer Sales Requirement, VOA, 28 June [online] http://www1.voanews.com/english/news/a-13-2009-06-25-voa55-68788912.html (accessed 27 March 2014).

VOA (2009b) Chinese Netizens Celebrate Green Dam Delay, VOA, 01 July [online] $\mathrm{http} / /$ www1.voanews.com/english/news/a-13-2009-07-01-voa14-68700632.html (accessed 27 March 2014).

Zittrain J. and Edelman, B. (2003) Empirical Analysis of Internet Filtering in China, Berman Center for Internet and Society, April [online]

http://cyber.law.harvard.edu/sites/cyber.law.harvard.edu/files/2003-02.pdf (accessed 28 January 2015).

\section{Notes}

1 There might also be some 'positive effects' that the regulator does not expect but in fact benefit the society.

2 For detail discussions on the comprehensive mechanisms for internet content regulation in China, please see Liao (2004).

3 For detailed discussions on the 'real name registration' and its implications, please see Liao (2015).

4 E.g., the Taiping Heaven Movement, the Bailianjiao, among others, in the 19 century seeking to overturn the Qing Dynasty. 